\title{
Effect of uterine contractions on left atrial pressure in a pregnant woman with mitral stenosis
}

\author{
Peter Jakobi, Zvi Adler, Etan Z Zimmer, \\ Simcha Milo
}

Rambam Medical Centre, Technion-Faculty of Medicine, Haifa, Israel 31096

Peter Jakobi, MD, senior registrar in obstetrics and gynaecology

Zvi Adler, MD, surgical registrar in cardiac surgery Etan Z Zimmer, MD, consultant in obstetrics and gynaecology

Simcha Milo, MD, senior lecturer in cardiac surgery

Correspondence to:

Dr Jakobi.

BrMed f 1989;298:27.
Several studies of peripartum haemodynamics in normal pregnancies have been performed. ${ }^{1-3}$ The results, however, are somewhat confusing, probably because of methodological factors and the use of indirect methods to assess haemodynamic variables. ${ }^{3}$ We are aware of only one study on peripartum haemodynamics in parturients with mitral stenosis in which a pulmonary artery catheter was used, but measurements were made only between contractions. ${ }^{+}$ We present a case showing a relation between direct measurements of left atrial pressure and uterine contractions in a pregnant woman during and after a closed mitral valve commissurotomy.

\section{Case report}

A 32 year old woman in the 33rd week of her first pregnancy was referred for closed mitral valve commissurotomy after pulmonary oedema developed for no apparent cause after her admission to hospital with heart failure due to mitral valve disease. The area of the mitral valve on two dimensional echocardiography was only $1 \cdot 1 \mathrm{~cm}^{2}$. During and after the operation continuous external monitoring of fetal heart rate and uterine activity was performed. The direct left atrial pressure, which was $26 \mathrm{~mm} \mathrm{Hg}$ before the operation, dropped to $16 \mathrm{~mm} \mathrm{Hg}$ after it. As the left atrium was closed unexplained periodic increases in left atrial pressure were seen similar to the values before the commissurotomy. We then noticed that uterine contractions had started. On further observation it became obvious that the changes in left

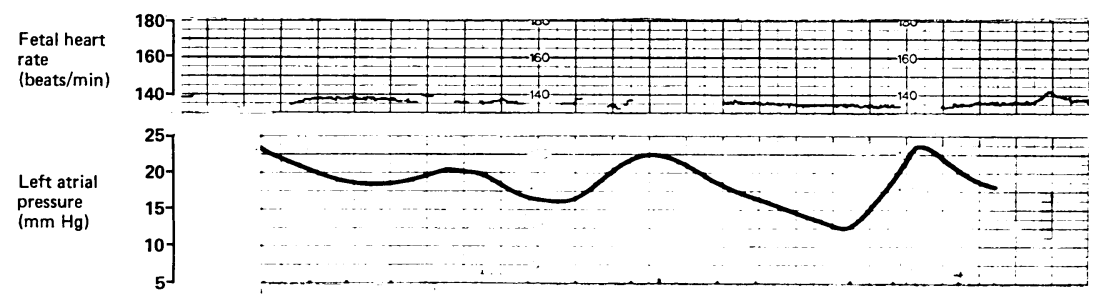

Uterine

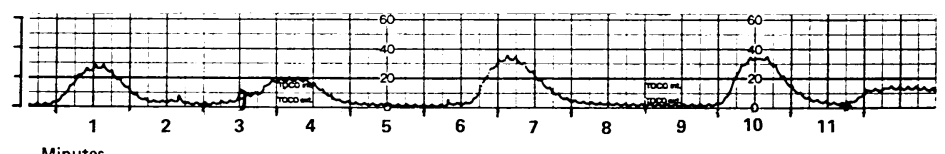

Minutes

Record from external monitor of fetal heart rate and uterine contractions. Left atrial pressure values were superimposed manually (paper speed $20 \mathrm{~cm} / \mathrm{min}$ ) atrial pressure mimicked the contractions. The figure shows the left atrial pressure recorded on the printout from the fetal monitor.

The contractions occurred every three minutes. The left atrial pressure ranged from 13-19 $\mathrm{mm} \mathrm{Hg}$ between contractions to $21-27 \mathrm{~mm} \mathrm{Hg}$ during and immediately after contractions. The mean left atrial pressure measured during 17 contractions was $23.2 \mathrm{~mm} \mathrm{Hg}$, whereas the mean of the nadirs was $16.4 \mathrm{~mm} \mathrm{Hg}$. The average difference, $6.8 \mathrm{~mm} \mathrm{Hg}$, was significant $(p<0 \cdot 001)$. This association between left atrial pressure and uterine activity was also documented in the recovery room four hours after the operation.

\section{Comment}

In normal pregnancy maternal blood volume, heart rate, and cardiac output are considerably increased. During uterine contractions, depending on maternal posture, an additional increase in cardiac output and stroke volume has been found (W Lee, paper presented at 8th annual meeting of the Society of Perinatal Obstetricians, Las Vegas, 1988). In mitral stenosis the cardiac output is fairly fixed, and patients might be unable to cope with the increase in stroke volume that occurs during uterine contractions. Clark et al found a significant increase in the pulmonary capillary wedge pressure during the immediate postpartum period. ${ }^{4}$ No data were given, however, on the relation between haemodynamic changes and uterine contractions. In our patient, even after commissurotomy, the left atrial pressure during contractions was in the range at which pulmonary congestion or even pulmonary oedema occurs. As the uterine activity was monitored externally the exact intensity of contractions was unknown. The patient's cervical score, however, did not change, leading to the assumption that these contractions were ineffective and of fairly low intensity. Yet they were enough to cause haemodynamic impairments.

We suggest that in pregnant women with known mitral stenosis uterine activity (even premature or Braxton Hicks type) may cause acute heart failure and pulmonary oedema "of unknown origin." These contractions should be treated immediately and aggressively and be considered among possible trigger mechanisms for heart failure. An operation before delivery may be indicated in these patients.

1 Ueland $\mathrm{K}$, Hansen JM. Maternal cardiovascular dynamics. II. Posture and uterine contractions. Am f Obstet Gynecol 1969;103:1-7.

Metcalfe J, Mcanulty JH, Ueland K. Cardiovascular physiology. Clin Obstet Gynecol 1981;24:693-710.

3 Robson SC, Dunlop W, Hunter S. Cardiac output during labour. Br Med $\mathcal{f}$ 1987;295:1169-72

4 Clark SL, Phelan JP, Greenspoon J, Aldahl D, Horenstein J. Labor and delivery in the presence of mitral stenosis: central hemodynamic observations. Am f Obstet Gynecol 1985;152:98+-8.

(Accepted 19 September 1988
Steno Memorial Hospital, DK-2820 Gentofte,

Denmark

Tonny Jensen, $\mathrm{MD}$, research fellow

BrMed f 1989;298:27-8

\section{Increased plasma concentration of von Willebrand factor in insulin dependent diabetics with incipient nephropathy}

\section{Tonny Jensen}

Much of the excess mortality in diabetics with clinical nephropathy is caused by cardiovascular disease, ${ }^{\prime}$ but despite the presence of known cardiovascular risk factors, such as raised blood pressure and atherogenic lipoprotein abnormalities, this increase in mortality has not been fully explained. According to the response to injury hypothesis, "injury" to the endothelium is the initiating event in atherogenesis, and an increased plasma concentration of von Willebrand factor possibly reflects generalised endothelial cell injury. Moreover, increased release of this factor from endothelial cells provides opportunities for thrombosis. We therefore investigated whether diabetics with increased urinary albumin excretion had an increased plasma concentration of von Willebrand factor.

\section{Patients, methods, and results}

We studied 75 non-obese patients with insulin dependent diabetes (onset before age 31). They had no 